\title{
Precautionary Practices of Respiratory Therapists and Other Health- Care Practitioners Who Administer Aerosolized Medications
}

\author{
Rebecca J Tsai PhD, James M Boiano MSc CIH, Andrea L Steege PhD MPH, \\ and Marie H Sweeney PhD MPH
}

\begin{abstract}
BACKGROUND: Respiratory therapists (RTs) and other health-care workers are potentially exposed to a variety of aerosolized medications. The National Institute for Occupational Safety and Health (NIOSH) Health and Safety Practices Survey of Healthcare Workers describes current exposure control practices and barriers to using personal protective equipment during administration of selected aerosolized medications. METHODS: An anonymous, multi-module, web-based survey was conducted among members of health-care professional practice organizations representing RTs, nurses, and other health-care practitioners. A module on aerosolized medications included submodules for antibiotics (amikacin, colistin, and tobramycin), pentamidine, and ribavirin. RESULTS: The submodules on antibiotics, pentamidine, and ribavirin were completed by 321, 227, and 50 respondents, respectively, most of whom were RTs. The relatively low number of ribavirin respondents precluded meaningful interpretation of these data and may reflect the rare use of this drug. Consequently, analysis focused on pentamidine, classified by NIOSH as a hazardous drug, and the antibiotics amikacin, colistin, and tobramycin, which currently lack authoritative safe handling guidelines. Respondents who administered pentamidine were more likely to adhere to good work practices compared with those who administered the antibiotics. Examples included training received on safe handling procedures $(75 \%$ vs $52 \%)$, availability of employer standard procedures (82\% vs 55\%), use of aerosol delivery devices equipped with an expiratory filter (96\% vs $53 \%)$ or negative-pressure rooms $(61 \%$ vs $20 \%)$, and always using respiratory protection (51\% vs $13 \%$ ). CONCLUSIONS: Despite the availability of safe handling guidelines for pentamidine, implementation was not universal, placing workers, co-workers, and even family members at risk of exposure. Although the antibiotics included in this study lack authoritative safe handling guidelines, prudence dictates that appropriate exposure controls be used to minimize exposure to the antibiotics and other aerosolized medications. Employers and employees share responsibility for ensuring that precautionary measures are taken to keep exposures to all aerosolized medications as low as practicable. Key words: aerosolized medications; respiratory therapists; exposure controls; pentamidine; antibiotics; web-based survey. [Respir Care 2015;60(10):1409-1417]
\end{abstract}

\section{Introduction}

Aerosolized medications are used to treat respiratory infections and other pulmonary ailments via inhalation ther-

\footnotetext{
The authors are affiliated with the Division of Surveillance, Hazard Evaluations, and Field Studies, National Institute for Occupational Safety and Health, Centers for Disease Control and Prevention, Cincinnati, Ohio.

Supplementary material related to this paper is available at http://www. rcjournal.com.
}

apy. Nebulizers are commonly used to deliver a fine spray or mist containing one or more medications that can be

\footnotetext{
All authors are federal government employees, and preparation of this manuscript was completely funded by the United States Government. Otherwise, no additional financial disclosures were reported by the authors of this paper. The findings and conclusions in this paper are those of the authors and do not necessarily represent the views of the National Institute for Occupational Safety and Health. Mention of company names or products does not constitute endorsement by the National Institute for Occupational Safety and Health.
} 
directly inhaled from the mouthpiece of the device. ${ }^{1}$ Aerosol generators have also been used to treat pediatric patients (eg, with ribavirin) inside containment hoods or tents. Aerosolized medications may be preferred over systemic therapy for several reasons: the medication can be delivered to a specific site, lower dosage can achieve high drug concentrations in the lungs, and the potential for systemic adverse effects is reduced. ${ }^{2,3}$ Despite their inherent benefits, aerosolized medications may pose an occupational hazard to respiratory therapists (RTs) and other healthcare workers who administer them. Unintentional inhalation of fugitive aerosols can occur when the nebulizer mouthpiece or mask is improperly fitted or separated from the patient's mouth (eg, when coughing). ${ }^{4-6}$ Although exposure to aerosolized medications among caregivers is relatively low compared with the patients receiving treatment, adverse effects in occupationally exposed workers have been reported. ${ }^{1,7}$

The following aerosolized medications were included in this study: antibiotics (amikacin, colistin, and tobramycin), antiprotozoal (pentamidine), and antiviral (ribavirin). The targeted aerosolized antibiotics have been associated with respiratory irritation, ototoxicity, and nephrotoxicity (amikacin); rhinitis, asthma, and dyspnea (colistin); and eye irritation and asthma-like symptoms (tobramycin). ${ }^{8-10}$ Primary health effects associated with occupational exposure to pentamidine include dyspnea, chest tightness, cough, conjunctivitis, hematologic abnormalities, perinasal paresthesia, and numbness. ${ }^{11,12}$ Aerosolized pentamidine also has been shown to be embryotoxic in animals. ${ }^{13}$ Respiratory irritation, shortness of breath, ocular irritation, asthma, and skin rash have been reported by health-care workers administering aerosolized ribavirin. ${ }^{14}$ Ribavirin has also been shown to be teratogenic (in rodents), which has prompted precautionary guidelines for health-care workers of child-bearing age. ${ }^{15}$ Evidence of pentamidine and ribavirin exposure has been detected in the urine of exposed health-care workers. ${ }^{4,16,17}$ Surveys of RTs have reported an increased risk of occupational asthma and other respiratory symptoms. ${ }^{18-20}$

This research was supported by the National Institute for Occupational Safety and Health. The authors have disclosed no conflicts of interest.

Mr Boiano presented a version of this paper via webinar to American Association for Respiratory Care members on August 21, 2013.

Correspondence: Rebecca J Tsai PhD, Division of Surveillance, Hazard Evaluations, and Field Studies, National Institute for Occupational Safety and Health (NIOSH), 1090 Tusculum Avenue, MS R-17, Cincinnati, OH 45226-1998. E-mail: rtsai@cdc.gov.

DOI: $10.4187 /$ respcare. 03817

\section{QUICK LOOK}

\section{Current knowledge}

Aerosolized medications are commonly used to treat respiratory infections and other pulmonary diseases. Nebulizers are used to deliver aerosol containing one or more medications that can be directly inhaled from the mouthpiece of the device. Aerosolized medications may be preferred over systemic therapy for several reasons: the ability to deliver medication to a specific site, the possibility of using a lower dosage to achieve high drug concentrations in the lungs, and the potential for reducing systemic adverse effects. Despite their inherent benefits, aerosolized medications may pose an occupational hazard to respiratory therapists and other health-care workers who administer them. Although exposure to aerosolized medications among caregivers is relatively low compared with exposure of the patients receiving treatment, adverse effects in occupationally-exposed workers have been reported.

\section{What this paper contributes to our knowledge}

In a survey of caregivers, precautionary practices were not universally used during administration of aerosolized medications. Training, availability of employer standard operating procedures, and use of engineering controls and personal protective equipment were more prevalent for pentamidine than for antibiotics, probably because of the longstanding safe handling guidelines for hazardous drugs, including pentamidine. However, adherence to precautionary guidelines for pentamidine was not universal. Research is needed to determine whether aerosolized antibiotics pose a health risk to workers. Until then, a precautionary approach should prevail.

The National Institute for Occupational Safety and Health (NIOSH) and the Occupational Safety and Health Administration (OSHA) consider pentamidine and ribavirin hazardous drugs and have developed guidelines for the safe handling of both medications. ${ }^{15,21}$ These guidelines provide information on recommended exposure controls to protect health-care workers from exposure and adverse health effects. Unless a hazard can be eliminated or substituted by a substance less toxic (which is not feasible with respect to aerosolized medications), exposure controls should be systematically implemented in the following decreasing order of efficacy: (1) engineering controls, (2) administrative controls, (3) work practice controls, and (4) personal protective equipment (PPE).22 Authoritative guidelines for safe handling of the targeted aerosolized 


\section{Precautionary Practices for Administration of Aerosolized Medications}

antibiotics do not exist; they have not been linked to serious health effects.

Training and standard procedures, often part of a comprehensive health and safety program, are important for reducing exposure to aerosolized medications. ${ }^{23} \mathrm{~A}$ NIOSH Alert $^{21}$ recommends the implementation of such a program for handling hazardous drugs. Additionally, the American Society of Health-System Pharmacists guidelines ${ }^{24}$ state that only trained workers should administer hazardous drugs. Standard procedures should stipulate the use of appropriate engineering and administrative controls and PPE to minimize exposure of health-care personnel to aerosolized medications during treatment of patients. ${ }^{5,24}$ Engineering controls are effective at removing fugitive aerosols at the source. ${ }^{25}$ These may include continuous aerosol delivery systems equipped with expiratory filters or ventilated booths equipped with high-efficiency particulate air (HEPA) filters. ${ }^{1,5}$ Multiple engineering controls, including the use of negative-pressure rooms, in combination with these devices may also be used to further protect healthcare workers.

The primary objective of this study was to describe self-reported work practices of RTs and other health-care workers who administer aerosolized amikacin, colistin, tobramycin, pentamidine, and ribavirin. This national survey is the first to examine the use of engineering, administrative, and work practice controls and PPE by health-care workers administering the targeted aerosolized medications.

\section{Methods}

\section{Survey Methodology}

Data used in this study are from the NIOSH Health and Safety Practices Survey of Healthcare Workers, an anonymous, multi-module, web-based survey conducted from January 28 through March 29, 2011. The study population included members of professional practice organizations representing health-care occupations that routinely use or come in contact with several classes of chemical agents prominently found in health care. Practices regarding the administration of aerosolized medications were addressed by one of 7 hazard modules targeted to members of the American Association for Respiratory Care, the largest professional practice organization representing RTs. Other health-care workers who administered aerosolized medications were also invited to complete the survey module. Methods used in the design, testing, and implementation of the survey and its strengths and limitations have been described elsewhere. ${ }^{26}$

\section{Survey Instrument}

The hazard module addressing aerosolized medications consisted of 3 submodules: (1) antibiotics (amikacin, colistin, and tobramycin); (2) pentamidine; and (3) ribavirin. The topic areas covered by this module can be found in the supplementary materials at http://www.rcjournal.com. The submodules for antibiotics and pentamidine contained 29 questions each, whereas the submodule for ribavirin contained 31 questions. Question format included yes/no, multiple choices, and multiple options (check all that apply). In cases in which responses were not exhaustive, respondents could select "other" and type in a response.

The modular survey was programmed to present the most relevant hazard module first based on screening questions, then the core module, and then a second hazard module, if indicated. It was possible for respondents to complete the aerosolized medication module and not the core module. In those cases, demographic information is unavailable.

\section{Data Analysis}

Data were analyzed using SAS 9.3 (SAS Institute, Cary, North Carolina). Simple frequencies and prevalences are presented for questions in the aerosolized medication submodules and selected questions in the core module that describe demographic, employer, and occupation characteristics. We compared responses from all respondents and from RTs to questions addressing training, availability of employer procedures, use of aerosol delivery equipment/engineering controls, and use of PPE to determine whether prevalence changed substantively. Because no differences were observed, the data for all respondents are reported. Either the Pearson chi-square test or the Fisher exact test (at least one cell with an expected value $<5$ ) was used to assess differences in health-care practices between antibiotics and pentamidine.

The time frame for most questions on aerosolized antibiotics and ribavirin was the past 7 calendar d, whereas for pentamidine, it was the past 30 calendar $\mathrm{d}$. A longer time period for pentamidine was used to maximize the number of respondents because it was administered less frequently than the other medications, based on input from practitioners. For a question addressing use of engineering controls, the survey was programmed to present 2 response scenarios: yes or no when the aerosolized medication was administered only one time in the past 7 calendar $d$ or every time, sometimes, or never when administered more than one time. For analysis, frequencies of yes, every time, and sometimes were combined as yes responses; frequencies of no and never were combined as no responses. Additionally, respondents were asked to select reason(s) for not always using each of 4 types of PPE (ie, protective 


\section{Precautionary Practices for Administration of Aerosolized Medications}

gloves, water-resistant gowns or outer garment, eye/face protection, and respirator). Each reason for not always wearing PPE was subsequently summarized across all 4 types of PPE. The percentage of respondents was obtained by calculating the number of respondents who did not always use any one of the 4 types of PPE due to a specified reason divided by the total number of respondents (including those who reported always wearing PPE). Each respondent was counted once for each reason, even if the same reason was given for more than one type of PPE. The age of a respondent was estimated by subtracting the year of birth from the year the survey was administered. States where respondents worked were aggregated into 4 United States Census regions (Northeast, Midwest, South, and West) for reporting purposes. Because the primary intent of this survey was to provide descriptive information on precautionary practices regarding administration of aerosolized medications, no a priori hypotheses were proposed.

\section{Human Subject Review}

The NIOSH institutional review board determined that the activities in this project were surveillance and did not meet the criteria of research according to 45 CFR 46.1101(b)(2) and Centers for Disease Control and Prevention guidelines for defining public health research and public health nonresearch. ${ }^{27}$

\section{Results}

\section{Respondent Characteristics}

A total of 491 respondents completed one or more submodules of the aerosolized medications hazard module. Submodules on antibiotics, pentamidine, and ribavirin were completed by 321,227 , and 50 respondents, respectively. The core module was completed by 285 (89\%), 201 (89\%), and $40(80 \%)$ of these respondents, respectively, and can be characterized by demographic data. The relatively low number of respondents to the ribavirin submodule precludes meaningful interpretation of the data; therefore, no additional data on ribavirin practices will be presented. We provide descriptive information on respondent demographic and administration characteristics for aerosolized antibiotics and pentamidine in supplementary Tables 1 and 2 (http://www.rcjournal.com).

Demographic, occupation, and employer characteristics for respondents of the antibiotics and pentamidine submodules were similar with respect to many characteristics (see supplementary Table 1). Most respondents of the antibiotics and pentamidine submodules were female $(65 \%$ and $70 \%$, respectively), white ( $88 \%$ and $91 \%$ ), and $>40 y$ of age ( $83 \%$ and $88 \%)$; possessed at least an associate's degree $(92 \%$ and $92 \%)$; spent $>50 \%$ of their time in direct patient care $(82 \%$ and $72 \%)$; had $\geq 11 \mathrm{y}$ in their current occupation (79\% and $81 \%$ ) and with their employer (55\% and 64\%); and did not belong to a labor union (90\% and $89 \%$ ). RTs represented $87 \%$ and $76 \%$ of the antibiotics and pentamidine submodules, respectively, with nurses comprising most of the remaining respondents. Employers were best characterized as hospitals having $>1,000$ employees ( $\geq 56 \%$ ), nonprofit ( $\geq 61 \%$ ), located in a large city ( $\geq 65 \%$ ), and fairly equally distributed across the 4 United States geographical regions.

\section{Administration Characteristics}

Antibiotics and pentamidine administration characteristics are presented in supplementary Table 2. Administration practices of respondents to the antibiotics submodule were best characterized as follows: $70 \%$ administered for $\geq 6 \mathrm{y}, 85 \%$ administered for $\leq 3 \mathrm{~d}$ in the past $7 \mathrm{~d}$, nearly $70 \%$ administered $<4$ times in the past $7 \mathrm{~d},>60 \%$ spent $<15$ min with a patient during a single administration, and $>90 \%$ delivered aerosol therapy in patients' hospital rooms. Administration practices of respondents to the pentamidine submodule were best characterized as follows: $>70 \%$ administered for $\geq 6 \mathrm{y}, 75 \%$ administered for $\leq$ $2 \mathrm{~d}$ in the past $30 \mathrm{~d},>90 \%$ administered only up to 5 times in the past $30 \mathrm{~d},>60 \%$ spent $\geq 15$ min with a patient during a single administration, and nearly $75 \%$ administered the medication in a clinic/department treatment room or area. Respondents administered pentamidine for more years and spent more time with patients per treatment than respondents who administered antibiotics. Both respondent groups reported that the number of times they had administered the medication was about the same as usual.

\section{Training and Employer Standard Administration Procedures}

Respondents were much less likely to receive training on the safe handling of antibiotics than on pentamidine (52\% vs $75 \%, P<.01$ ) (Table 1 ). This difference was further magnified $(45 \%$ vs $75 \%, P<.01)$ when respondents who administered both antibiotics and pentamidine were excluded from the analysis. However, of those who had received training, a slightly higher proportion of pentamidine respondents $(66 \%$ vs $59 \%, P=.21)$ reported being trained $>12$ months ago. Respondents administering antibiotics also reported that their employer was less likely to have standard administration procedures compared with those who administered pentamidine (55\% vs $82 \%, P<.01)$. 
Precautionary Practices for Administration of Aerosolized Medications

Table 1. Training and Employer Standard Procedures for Administering Aerosolized Antibiotics and Pentamidine

\begin{tabular}{|c|c|c|c|c|c|}
\hline \multirow{2}{*}{ Training/Standard Procedures } & \multicolumn{2}{|c|}{ Antibiotics* } & \multicolumn{2}{|c|}{ Pentamidine } & \multirow{2}{*}{$P \dagger$} \\
\hline & $n$ 末 & $\%$ Yes & $n \ddagger$ & $\% \mathrm{Yes}$ & \\
\hline Received training & 317 & 52 & 213 & 75 & $<.01$ \\
\hline Never received training & 317 & 48 & 213 & 25 & \\
\hline \multicolumn{6}{|l|}{ Time period for training } \\
\hline Within last $12 \mathrm{mo}$ & 165 & 41 & 160 & 34 & .21 \\
\hline$>12 \mathrm{mo}$ ago & 165 & 59 & 160 & 66 & \\
\hline Standard procedures & 307 & 55 & 214 & 82 & $<.01$ \\
\hline
\end{tabular}

Table 2. Use of Aerosol Delivery Equipment and Engineering Controls for Aerosolized Antibiotics and Pentamidine

\begin{tabular}{|c|c|c|c|c|c|}
\hline \multirow{2}{*}{ Question } & \multicolumn{2}{|c|}{ Antibiotics* } & \multicolumn{2}{|c|}{ Pentamidine } & \multirow{2}{*}{$P \dagger$} \\
\hline & $n \ddagger$ & $\%$ Never Using & $n \ddagger$ & $\%$ Never Using & \\
\hline \multicolumn{6}{|l|}{$\begin{array}{l}\text { When you administered aerosolized (antibiotics, pentamidine) } \\
\text { to patients during the past } 7 \text { calendar d, did you... }\end{array}$} \\
\hline administer in a negative-pressure room?§ & 295 & 80 & 194 & 39 & $<.01$ \\
\hline $\begin{array}{l}\text { use a handheld, continuous aerosol delivery system } \\
\text { (nebulizer, T-piece, mouthpiece) with an expiratory filter? }\end{array}$ & 293 & 47 & 195 & 4 & $<.01$ \\
\hline use a ventilator equipped with an expiratory HEPA filter? & 297 & 59 & NA & NA & \\
\hline $\begin{array}{l}\text { use a continuous aerosol delivery system attached to a face } \\
\text { mask, face tent, or tracheostomy collar? }\end{array}$ & 297 & 48 & NA & NA & \\
\hline $\begin{array}{l}\text { use a ventilated booth or treatment station equipped with a } \\
\text { HEPA filter? }\end{array}$ & NA & NA & 194 & 46 & \\
\hline \multicolumn{6}{|c|}{$\begin{array}{l}\text { * Antibiotics included tobramycin, amikacin, and colistin. } \\
\dagger \text { The chi-square test was used to calculate } P \text { values. } \\
\text { ¥ Number of respondents varied for individual items (ie, number of eligible respondents less number who elected not to answer). } \\
\S \text { A room with a ventilation system that creates negative-pressure and prevents air contaminates from escaping to other rooms/areas. } \\
\text { HEPA = high efficiency particulate air } \\
\text { NA = question was not asked for this aerosolized medication }\end{array}$} \\
\hline
\end{tabular}

\section{Use of Aerosol Delivery Equipment and Engineering Controls}

In some cases, the aerosol delivery equipment and engineering controls were unique to one medication (eg, ventilated booth or treatment station equipped with a HEPA filter for pentamidine). In other cases, the same devices/controls were applicable to both medications (eg, negative-pressure room, nebulizer with expiratory filter), and comparisons were made. Where the same controls/devices were used, $80 \%$ of respondents administering antibiotics and nearly $40 \%$ of respondents administering pentamidine never used a negative-pressure room $(P<.01)$. Additionally, nearly half $(47 \%)$ of the respondents administering antibiotics never used a handheld, continuous aerosol delivery system with an expiratory filter compared with only $4 \%$ of pentamidine respondents $(P<.01)$. About $46 \%$ of respondents administering pentamidine never used a ventilated booth or treatment station equipped with a HEPA filter. For engineering controls unique to antibiotics, nearly $60 \%$ of respondents never used a ventilator equipped with an expiratory HEPA filter, and $48 \%$ never used a continuous aerosol delivery system attached to a face mask, face tent, or tracheostomy collar (Table 2).

\section{PPE}

Frequency of Use and Reasons for Disuse. Respondents of both antibiotics and pentamidine submodules reported that they did not always use protective gloves $(21 \%$ vs $22 \%, P=.79$ ) and water-resistant gowns or outer garments ( $66 \%$ vs $69 \%, P=.47$ ). Nearly $88 \%$ of respondents administering antibiotics did not always use eye/face protection or respirators. By comparison, a smaller proportion of respondents administering pentamidine did not always use respirators $(49 \%, P<.01)$ or eye/face protection $(75 \%$, 


\section{Precautionary Practices for Administration of Aerosolized Medications}

Table 3. Percentage of Respondents Not Always Using PPE When Administering Aerosolized Antibiotics and Pentamidine

\begin{tabular}{|c|c|c|c|c|c|}
\hline \multirow{2}{*}{ Type of PPE } & \multicolumn{2}{|r|}{ Antibiotics* } & \multicolumn{2}{|c|}{ Pentamidine } & \multirow{2}{*}{$P \dagger$} \\
\hline & $n \ddagger$ & $\%$ Not Always Using & $n$ 末 & $\%$ Not Always Using & \\
\hline Protective gloves & 291 & 21 & 197 & 22 & .79 \\
\hline Water-resistant gown or outer garment & 293 & 66 & 199 & 69 & .47 \\
\hline Eye/face protection $\S$ & 290 & 88 & 192 & 75 & $<.01$ \\
\hline Respirator\| & 287 & 87 & 190 & 49 & $<.01$ \\
\hline \multicolumn{6}{|c|}{$\begin{array}{l}\text { * Antibiotics included tobramycin, amikacin, and colistin. } \\
\uparrow \text { The chi-square test was used to calculate } P \text { values. } \\
\text { ‡ Number of respondents varied for individual items (ie, number of eligible respondents less number who elected not to answer). } \\
\S \text { Examples included goggles and face shields. } \\
\| \text { Included an N95 respirator, a half-facepiece air-purifying respirator with particulate filter(s), and a powered air-purifying respirator with particulate filter(s). } \\
\text { PPE = personal protective equipment }\end{array}$} \\
\hline
\end{tabular}

Table 4. Reasons for Not Always Wearing Personal Protective Equipment When Administering Aerosolized Antibiotics and Pentamidine

\begin{tabular}{|c|c|c|c|}
\hline Reason & Antibiotics* $(n=290), \% \dagger$ & Pentamidine $(n=191), \% \dagger$ & $P \ddagger$ \\
\hline An engineering control was used§ & 8 & 27 & $<.01$ \\
\hline Not part of the protocol & 77 & 64 & $<.01$ \\
\hline (Skin) exposure was minimal\| & 29 & 31 & .62 \\
\hline No one else who does this work uses them & 20 & 10 & $<.01$ \\
\hline Not provided by employer & 19 & 11 & .02 \\
\hline Not readily available in work area & 20 & 11 & .01 \\
\hline Too uncomfortable or difficult to use & 4 & 4 & .66 \\
\hline Cross-contamination to other areas is not a concern $\mathbb{I}$ & 3 & 5 & .49 \\
\hline Concerned about raising the patient's anxiety & 1 & 2 & $.39 * *$ \\
\hline Other & 21 & 13 & .01 \\
\hline
\end{tabular}

* Antibiotics included tobramycin, amikacin, and colistin.

$\dagger$ Percentages add up to $>100 \%$ because respondents could select more than one reason.

$\ddagger$ Unless stated otherwise, the chi-square test was used to calculate $P$ values.

$\S$ This reason was not included as an option for protective gloves.

|| The response for eye/face protection and respirator was that exposure was minimal.

II This reason was not included as an option for eye/face protection and respirator.

** The Fisher exact test was used to calculate $P$.

$P<.01$ ) (Table 3). Approximately $90 \%$ of respondents of both submodules who wore respirators reported that they were fit-tested.

Respondents who reported that they did not always wear PPE when administering antibiotics and pentamidine were asked to select from a list of 10 reasons (including other, please specify) all applicable reasons for not always wearing PPE (Table 4). The reason most reported by respondents was that it was not part of the protocol. Statistically significant differences between those administering antibiotics and those administering pentamidine were found for the following reasons: an engineering control was being used $(P<.01)$, not part of the protocol $(P<.01)$, no one else who does this work uses them $(P<.01)$, not provided by the employer $(P=.02)$, not readily available in the work area $(P=.01)$, and other $(P=.01)$. Respondents also indicated that they were never trained to wear gloves/gowns or were not aware that gloves or gowns were needed. See supplementary Table 3 for results separated by type of PPE.

Glove Use: Activities in Which Cross-Contamination May Occur (Done While Wearing Gloves That Were Used to Handle Medications). Four percent of respondents who administered pentamidine and 3\% of respondents who administered antibiotics reported that they had removed and later reused gloves that had been worn during treatments $(P=.72)$ (Table 5). Respondents were also asked whether they performed selected activities while wearing gloves that had been used during administration. Activities most frequently reported by respondents who administered pentamidine included touching door knobs, cabinets, or drawers (41\%); using pens/pencils (36\%); and using a non-disposable stethoscope (36\%). Activities most frequently reported by respondents who administered antibiotics included touching intravenous pumps or bed con- 


\section{Precautionary Practices for Administration of Aerosolized Medications}

Table 5. Non-Recommended Practices Associated With the Use of Protective Gloves

\begin{tabular}{|c|c|c|c|}
\hline Practices While Wearing Protective Gloves & Antibiotics*, \% Yes & Pentamidine, $\%$ Yes & $P \dagger$ \\
\hline Reused gloves previously worn while administering aerosolized medications & $3(n=264) \neq$ & $4(n=164) \ddagger$ & .72 \\
\hline Activity performed while wearing gloves used to administer aerosolized medications§ & $(n=265)$ 末 & $(n=163) \ddagger$ & \\
\hline Touched intravenous pump or bed controls & 54 & 19 & $<.01$ \\
\hline Used pens/pencils & 51 & 36 & $<.01$ \\
\hline Touched waste basket/garbage bags & 28 & 22 & .18 \\
\hline Touched door knobs, cabinets, or drawers & 52 & 41 & .03 \\
\hline Used computer/calculator & 34 & 23 & .01 \\
\hline Handled files or charts & 9 & 13 & .25 \\
\hline Used non-disposable stethoscope & 50 & 36 & $<.01$ \\
\hline Used phone/cell phone or pager & 25 & 15 & .02 \\
\hline Ate, drank, chewed gum, or smoked & 5 & 3 & .45 \\
\hline Used restroom & 2 & 2 & $0.29 \|$ \\
\hline Applied cosmetics & $<1$ & 1 & $0.47 \|$ \\
\hline \multicolumn{4}{|c|}{$\begin{array}{l}\text { * Antibiotics included tobramycin, amikacin, and colistin. } \\
\dagger \text { Unless stated otherwise, the chi-square test was used to calculate } P \text { values. } \\
¥ \text { Number of respondents varied for individual items (ie, number of eligible respondents less number who elected not to answer). } \\
\S \text { Percentages add up to }>100 \% \text { because respondents could select more than one activity. } \\
\| \text { The Fisher exact test was used to calculate } P \text {. }\end{array}$} \\
\hline
\end{tabular}

trols (54\%); touching door knobs, cabinets, or drawers (52\%); and using pens/pencils (51\%). Respondents who administered antibiotics reported higher frequencies for all activities with the exception of handling files or charts.

Clothing Taken Home. Sixty percent $(n=175)$ of respondents administering antibiotics and $43 \%(n=85)$ of respondents administering pentamidine took home clothing that came in contact with these medications $(P<.01)$. Additionally, $12 \%$ and $16 \%$, respectively, did not know whether they had.

\section{Exposure Monitoring}

Exposure monitoring (ie, air and/or surface wipe sampling) was not common. Only $9 \%$ of respondents reported that monitoring had been conducted by their employer for pentamidine and a few percent for the antibiotics tobramycin and colistin. Amikacin was not included as a response option because it lacked a monitoring method. Approximately $40 \%$ of respondents reported that they did not know whether monitoring had been done for pentamidine or the 2 antibiotics.

\section{Discussion}

The NIOSH Health and Safety Practices Survey of Healthcare Workers is the first national survey to describe self-reported use of safe handling precautions by RTs and other health-care workers who administer aerosolized medications. This study provided an opportunity to compare exposure control practices for a hazardous drug (pentamidine), for which rigorous safe handling guidelines have been available for many years, and selected antibiotics, which currently lack comparable guidance. This study also showed that the number of ribavirin respondents was relatively low compared with the other studied medications, possibly indicating that ribavirin therapy has diminished.

Overall, survey findings showed that respondents who administered pentamidine were more likely to adhere to good work practices compared with those who administered antibiotics. Those who administered pentamidine were more likely to be trained, to be familiar with employer standard procedures, to have engineering controls in place, and to use eye/face protection and respirators. They were also less likely to touch various objects in the work area while wearing gloves that had been used to handle medications but were more likely to take home potentially contaminated clothing. Despite the longstanding availability of safe handling guidelines for pentamidine, adherence to these guidelines was not universal.

One fourth of respondents administering pentamidine were never trained. Of those who had received training, $66 \%$ reported that it was $>12$ months ago. Of those trained, a greater proportion of pentamidine respondents had received initial training but not annual refresher training compared with respondents who administered antibiotics. The latter finding was unexpected since refresher training is specified in safe handling guidelines. ${ }^{15}$ There are no specific training guidelines for antibiotics; however, the OSHA Hazard Communication Standard mandates ini- 


\section{Precautionary Practices for Administration of Aerosolized Medications}

tial training for all hazards in the workplace. ${ }^{28}$ Respondents who administered both pentamidine and antibiotics were more likely to be trained than those who administered antibiotics alone. It is very likely that the training on safe handling of pentamidine would be relevant to antibiotics.

Our findings show that $32 \%$ of respondents who administered antibiotics did not always use any of 4 engineering controls, raising concerns that RTs and others may be exposed to fugitive aerosols. Information regarding the concurrent use of multiple engineering controls and reasons for disuse was not collected, which limits full interpretation of these findings.

PPE should be worn to provide additional protection from exposure to aerosolized medications. Both the NIOSH and American Society of Health-System Pharmacists guidelines state that protective gloves and gowns should be worn while handling hazardous drugs. ${ }^{21,24}$ However, protective gloves and gowns were not always worn by $>20 \%$ and nearly $70 \%$ of respondents, respectively, while administering pentamidine. Also, a small percentage (3-4\%) of respondents who handled pentamidine and/or antibiotics reported reusing gloves, which may result in exposure and/or contamination of the work area. Additionally, respirators and eye/face protection should be worn when handling hazardous drugs. ${ }^{24}$ A previous study found that most workers did not wear respirators during the administration of pentamidine when local exhaust ventilation was available. ${ }^{29}$ This survey also found that respondents reported not wearing respirators when an engineering control was in place but documented that there were many additional reasons respondents did not wear respirators when administering pentamidine.

The barriers to using each type of PPE most reported by respondents who administered pentamidine and antibiotics (not part of the protocol, and skin exposure was minimal) suggest a perception among respondents that aerosolized medications pose a minimal exposure risk or that employers do not fully appreciate the potential adverse health effects associated with exposure to these drugs. The differences in reported reasons for not using PPE by respondents who administered pentamidine versus antibiotics may be attributable to the presence of safe handling guidelines for hazardous drugs, which currently apply only to pentamidine. The lack of information on potential synergistic effects of exposure to multiple medications, which are biologically active by nature, underscores a need for precautionary practices to minimize exposures.

This survey targeted a few of the many medications delivered as aerosols to patients. Without appropriate controls in place to minimize the likelihood of exposure to fugitive aerosols, RTs, nurses, and others who administer these and other aerosolized medications may be exposed unnecessarily. Data from this survey indicate that not all employers and employees handle pentamidine in accordance with OSHA guidelines. Although the antibiotics included in this study lack authoritative guidelines, prudence dictates that appropriate safe handling precautions be taken for antibiotics as well as other aerosolized medications. This comprehensive precautionary approach should minimize the risk of exposure of health-care practitioners and bystanders to fugitive aerosols during care of patients receiving aerosol therapy.

The limitations of this survey have been described elsewhere. ${ }^{26}$ However, there are 3 limitations specific to this hazard module. First, information on impediments to using aerosol delivery equipment and engineering controls was not collected and is recommended for future studies. Second, the relatively low number of respondents administering ribavirin prohibited meaningful interpretation of those data. Last, demographic information was unavailable for $\sim 10 \%$ of respondents who chose not to complete the core module.

\section{Conclusions}

Findings from this survey show that precautionary practices are not universally used during administration of aerosolized medications. Training, availability of employer standard procedures, and use of engineering controls and PPE were more prevalent for pentamidine than for the targeted antibiotics, most likely because of the longstanding safe handling guidelines for hazardous drugs, including pentamidine. However, adherence to precautionary guidelines for pentamidine was not universal, which is concerning. Research is needed to determine whether aerosolized antibiotics pose a health risk to workers. Until then, a precautionary approach should apply. The most commonly reported barriers associated with not using PPE suggest that employers and health-care workers are not aware of the hazards or believe that exposures are inconsequential or are so rare as to not warrant their use. Employers and employees share responsibility for ensuring that precautionary measures, including development and adherence to relevant standard procedures, are taken to keep exposures to all aerosolized medications as low as practicable.

\section{ACKNOWLEDGMENTS}

We thank Westat for collaboration in developing, testing, and conducting the survey. We are grateful to the professional practice organizations and their members who participated in the survey. We also thank Richard Branson MSc RRT FAARC and Joshua Harney for valuable comments and suggestions on an early draft of the manuscript. 


\section{Precautionary Practices for Administration of Aerosolized Medications}

\section{REFERENCES}

1. Jost M, Ahrens R, Beaudouin L, Eickmann U, Falcy M, Rüegger M. Occupational risk prevention in aerosol therapy (pentamidine, ribavirin). http://www.issa.int/details?uuid=c3ca6ed0-8658-4859-884fcbdd4c27fb65. Accessed February 17, 2015.

2. O'Hara CM, Anton WR, Gormley FX, Brazell C. Administration of aerosol pentamidine: a program design. J Assoc Nurses AIDS Care 1994;5(2):41-48.

3. Wood GC, Boucher BA. Aerosolized antimicrobial therapy in acutely ill patients. Pharmacotherapy 2000;20(2):166-181.

4. O'Riordan TG, Smaldone GC. Exposure of health care workers to aerosolized pentamidine. Chest 1992;101(6):1494-1499.

5. Gorman T, Dropkin J, Kamen J, Nimbalkar S, Zuckerman N, Lowe $\mathrm{T}$, et al. Controlling health hazards to hospital workers. New Solut 2013;23(Suppl):1-167.

6. Bothra M, Lodha R, Kabra SK. Tobramycin for the treatment of bacterial pneumonia in children. Expert Opin Pharmacother 2012; 13(4):565-571.

7. Montgomery AB, Corkery KJ, Brunette ER, Leoung GS, Waskin H, Debs RJ. Occupational exposure to aerosolized pentamidine. Chest 1990;98(2):386-388.

8. Antoniu SA, Cojocaru I. Inhaled colistin for lower respiratory tract infections. Expert Opin Drug Deliv 2012;9(3):333-342.

9. Neu HC. Tobramycin: an overview. J Infect Dis 1976;134(Suppl): S3-19.

10. Lane AZ, Wright GE, Blair DC. Ototoxicity and nephrotoxicity of amikacin: an overview of phase II and phase III experience in the United States. Am J Med 1977;62(6):911-918.

11. Green S, Nathwani D, Christie P, Kennedy D. Aerosolised pentamidine. Lancet 1989;2(8674):1284-1285.

12. Stanbury M, Gatti E, Sokolowski JW. Reactive airways dysfunction syndrome in a nurse exposed to pentamidine. J Occup Environ Med 1996;38(4):330-331.

13. Harstad TW, Little BB, Bawdon RE, Knoll K, Roe D, Gilstrap LC 3rd. Embryofetal effects of pentamidine isethionate administered to pregnant Sprague-Dawley rats. Am J Obstet Gynecol 1990;163(3): 912-916.

14. Munzenberger PJ, Walker PC. Protecting hospital employees and visitors from aerosolized ribavirin. Am J Hosp Pharm 1994;51(6): 823-826.
15. Occupational Safety and Health Administration. Controlling occupational exposure to hazardous drugs. In: OSHA technical manual (OTM), TED1-015A, Section VI, Chapter 2. 1999.

16. Smaldone GC, Vinciguerra C, Marchese J. Detection of inhaled pentamidine in health care workers. N Engl J Med 1991;325(12): 891-892.

17. Shults RA, Baron S, Decker J, Deitchman SD, Connor JD. Health care worker exposure to aerosolized ribavirin: biological and air monitoring. J Occup Environ Med 1996;38(3):257-263.

18. Dimich-Ward H, Wymer ML, Chan-Yeung M. Respiratory health survey of respiratory therapists. Chest 2004;126(4):1048-1053.

19. Kern DG, Frumkin H. Asthma in respiratory therapists. Ann Intern Med 1989;110(10):767-773.

20. Christiani DC, Kern DG. Asthma risk and occupation as a respiratory therapist. Am Rev Respir Dis 1993;148(3):671-674.

21. Centers for Disease Control and Prevention. Preventing occupational exposures to antineoplastic and other hazardous drugs in health care setting. NIOSH Alert 2004, DHHS NIOSH Publication 2004-165.

22. Manuele FA. Risk assessment and hierarchy of control. Prof Safety 2005;50:33-39.

23. Gardenhire DS, Ari A, Hess D, Myers TR. A guide to aerosol delivery devices for respiratory therapists, 3rd edition. http://www.aarc.org//app/ uploads/2014/08/aerosol_guide_rt.pdf. Accessed February 17, 2015.

24. American Society of Health-System Pharmacists. ASHP guidelines on handling hazardous drugs. Am J Health Syst Pharm 2006;63: 1172-1193.

25. McDiarmid MA, Fujikawa J, Schaefer J, Weinmann G, Chaisson RE, Hudson CA. Health effects and exposure assessment of aerosolized pentamidine handlers. Chest 1993;104(2):382-385.

26. Steege AL, Boiano JM, Sweeney MH. NIOSH Health and Safety Practices Survey of Healthcare Workers: training and awareness of employer safety procedures. Am J Ind Med 2014;57(6):640-652.

27. Centers for Disease Control and Prevention. Distinguishing public health research and public health nonresearch. http://www.cdc.gov/ od/science/integrity/docs/cdc-policy-distinguishing-public-healthresearch-nonresearch.pdf. Accessed February 17, 2015.

28. Occupational Safety and Health Administration. Hazard communication standard 29 CFR 19010.1200. https://www.osha.gov/pls/ oshaweb/owadisp.show_document?p_table $=$ STANDARDS\&p_id $=$ 10099. Accessed February 17, 2015.

29. Balmes JR, Estacio PL, Quinlan P, Kelly T, Corkery K, Blanc P. Respiratory effects of occupational exposure to aerosolized pentamidine. J Occup Environ Med 1995;37(2):145-150. 